\title{
Neutrino projects are poles apart, says panel
}

\section{Geoff Brumfiel, Washington}

It's not just distance that separates the two neutrino projects planned by the United States - their scientific objectives are clearly different too, according to a review by the National Academy of Sciences.

The report was commissioned earlier this year by the White House Office of Science and Technology Policy (OSTP) to clarify the degree of overlap between the proposed IceCube neutrino detector in Antarctica and the National Underground Science Laboratory (NUSL), which would probably be built at Lead, South Dakota (see Nature 417, 5; 2002).

The academy panel was chaired by Barry Barish, a physicist at the California Institute of Technology in Pasadena. This month's report describes the two projects as distinct, saying that there is "essentially no overlap or redundancy in their primary science goals".

John Marburger, director of the OSTP, says that although the report confirms the projects are scientifically distinct, they will end up competing for money in any case.

Neutrinos are subatomic particles with no electric charge and very small mass. They seldom interact with other particles and are not deflected by electromagnetic fields, so they can travel unhindered through

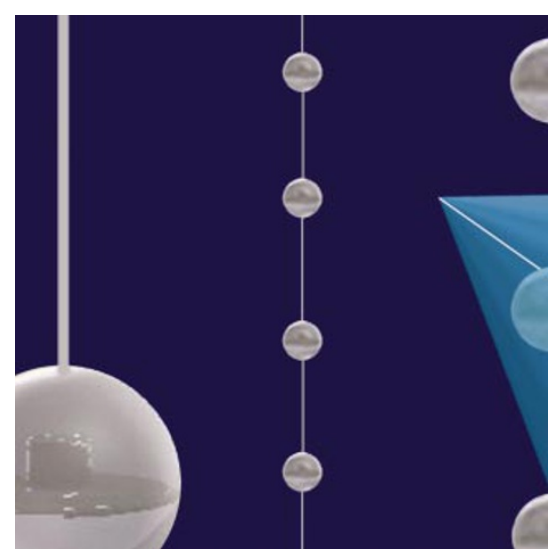

Simulation: strings of light-sensitive detectors in IceCube, one of two proposed neutrino projects.

turbulent regions of space. "Recent discoveries have created special opportunities to use neutrinos in new ways to advance our knowledge of the Universe and the laws that govern it," the panel finds.

The planned projects both aim to detect these elusive particles, but from different sources and for different reasons. IceCube would monitor a cubic-kilometre block of Antarctic ice for the rare flashes of light that occur when neutrinos interact with water molecules. The sheer size of IceCube means that it should detect neutrinos generated by powerful events outside our Galaxy, giving astrophysicists a new way to observe phenomena such as black holes. The neutrinos might also shed light on other high-energy particles that inhabit intergalactic space.

By contrast, the NUSL, a laboratory that would have facilities $2-4.5 \mathrm{~km}$ below ground, would study the properties of neutrinos generated closer to home - by the Sun and by particle accelerators on Earth. Its experiments would be aimed at improving researchers' understanding of neutrinos themselves and of the fundamental nature of matter.

But despite their differences, the two projects have some things in common: each is projected to cost about a quarter of a billion dollars to build, and each has already lined up some enthusiastic backers in Congress. IceCube, for example, secured $\$ 15$ million in funding in 2002 and could receive another $\$ 25$ million next year (see Nature 418, 573; 2002).

But the panel's sterling endorsement of both projects is no guarantee that either will proceed. The National Science Foundation and Department of Energy will now review the findings and decide whether to include them in future budget requests.

\section{Corporate chiefs told to follow animal urges}

John Whitfield, London

Three British zoologists have set up a consultancy firm that plans to sell ideas gleaned from the study of animal behaviour to corporate clients.

Animals and businesses face many of the same problems, argues one of the group, Alex Kacelnik of the University of Oxford. "A petroleum company forages for oil in much the same way as a starling might forage for worms," he says. The basic choice

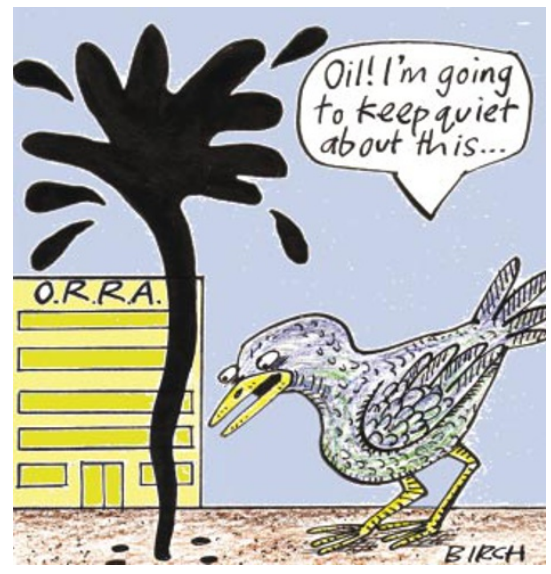

they face, he points out, is whether to stay in a field that is productive but in decline, or to move on and take a chance elsewhere.

Kacelnik's work on starlings has led him to believe that humans and other animals approach risk in similar ways. He now plans to apply his models of how animals cope with uncertainty through the consultancy firm Oxford Risk Research and Analysis (ORRA), which he founded last month with two other Oxford zoologists, John Krebs, chair of the UK Food Standards Agency, and Ed Mitchell. ORRA aims to study companies' decision-making processes, identify areas where risks are being misjudged, and recommend remedies.

The consultancy has already started work with clients in the pharmaceutical and energy industries, a university statement said. In work for one multinational client, it found that decisionmakers tended to be too cautious about doing business in unfamiliar regions, but were too gung-ho about investing where they knew. ORRA recommended changes in where and when the client made decisions, and called for more contact between its different operations.
It is too early to say whether any of ORRA's clients will follow its recommendations, Kacelnik says. The company has worked on three projects so far, and aims to have about a dozen, along with five full-time employees, by the end of its first year's operations.

Outside observers say that the consultancy's approach may prove alluring. "Companies are willing to explore any viable approach to dealing with risk and using it to their advantage," says Richard Apostolik, president of the Global Association of Risk Professionals, based in Jersey City, New Jersey. But to prosper, he adds, ORRA will have to show clients tangible results.

Animal behaviour can teach us much about human decision-making, says psychologist Daniel Read of the London School of Economics. But he urges caution: "Animals have the product of millions of years of evolution, but they can't take that knowledge and apply it to new environments." In situations where humans get the chance to stop and think things through, Read argues, animal behaviour may not be a very useful model. 